NASA

Technical Memorandum 107541
Army Research Laboratory Technical Report ARL-TR-1448

\title{
Laser Anemometer Measurements of the Flow Field in a 4:1 Pressure Ratio Centrifugal Impeller
}

G.J. Skoch

U.S. Army Research Laboratory

Lewis Research Center

Cleveland, Ohio

P.S. Prahst

NYMA, Inc.

Brook Park, Ohio

M.P. Wernet, J.R. Wood, and A.J. Strazisar

Lewis Research Center

Cleveland, Ohio

Prepared for the

Turbo-Expo '97

sponsored by the International Gas Turbine Institute of the American Society of Mechanical Engineers Orlando, Florida, June 2-5, 1997

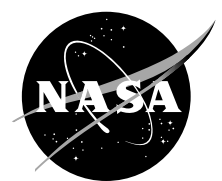

National Aeronautics and

Space Administration

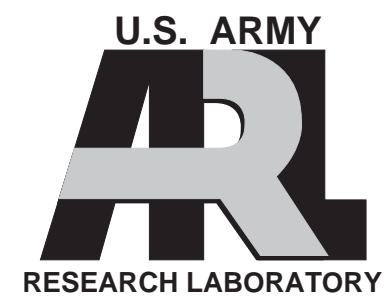




\section{LASER ANEMOMETER MEASUREMENTS OF THE FLOW FIELD IN A 4:1 PRESSURE RATIO CENTRIFUGAL IMPELLER}

\author{
G. J. Skoch \\ U. S. Army Research Laboratory \\ Cleveland, Ohio 44135
}

\author{
P. S. Prahst \\ NYMA Inc. \\ Brook Park, Ohio 44124
}

\author{
M. P. Wernet, J. R. Wood, A. J. Strazisar \\ NASA Lewis Research Center \\ Cleveland, Ohio 44135
}

\begin{abstract}
A laser-doppler anemometer was used to obtain flow-field velocity measurements in a $4: 1$ pressure ratio, $4.54 \mathrm{~kg} / \mathrm{s}(10 \mathrm{lbm} / \mathrm{s})$, centrifugal impeller, with splitter blades and backsweep, which was configured with a vaneless diffuser. Measured through-flow velocities are reported for ten quasi-orthogonal survey planes at locations ranging from $1 \%$ to $99 \%$ of main blade chord. Measured through-flow velocities are compared to those predicted by a $3-\mathrm{D}$ viscous steady flow analysis (Dawes) code.
\end{abstract}

The measurements show the development and progression through the impeller and vaneless diffuser of a through-flow velocity deficit which results from the tip clearance flow and accumulation of low momentum fluid centrifuged from the blade and hub surfaces. Flow traces from the CFD analysis show the origin of this deficit which begins to grow in the inlet region of the impeller where it is first detected near the suction surface side of the passage. It then moves toward the pressure side of the channel, due to the movement of tip clearance flow across the impeller passage, where it is cut by the splitter blade leading edge. As blade loading increases toward the rear of the channel the deficit region is driven back toward the suction surface by the cross-passage pressure gradient. There is no evidence of a large wake region that might result from flow separation and the impeller efficiency is relatively high. The flow field in this impeller is quite similar to that documented previously by NASA Lewis in a large low-speed backswept impeller.

\section{NOMENCLATURE}

$\mathrm{N} \quad=$ rotational speed, $\mathrm{rev} / \mathrm{min}$

$\mathrm{N}_{\text {design }} \quad=$ design rotational speed, rev/min

$\mathrm{N}_{\mathrm{cpp}} \quad$ = number of measurement bins per passage
PS = pressure surface of a blade

SS = suction surface of a blade

$U_{\text {tip }}=$ tip velocity at impeller exit, $\mathrm{m} / \mathrm{s}$

$\mathrm{V}_{\mathrm{abs}}=$ absolute velocity in the laser measurement plane, $\mathrm{m} / \mathrm{s}$

$\mathrm{V}_{\mathrm{qm}}=$ velocity component normal to beam path in the meridional plane. Also referred to as through-flow velocity, $\mathrm{m} / \mathrm{s}$

$\mathrm{V}_{\theta}=$ velocity component in direction of rotation, $\mathrm{m} / \mathrm{s}$

$\mathrm{x}^{\prime}=$ through-flow direction in the laser measurement plane

$\theta=$ circumferential direction

$\beta=$ absolute flow angle in measurement plane, $\beta=\tan ^{-1}\left(\mathrm{~V}_{\theta} / \mathrm{V}_{\mathrm{qm}}\right)$

$\beta_{\min }=$ minimum flow angle at each downstream radius ratio and span

\section{INTRODUCTION}

Laser anemometry has been used by several investigators to obtain measurements of the flow fields within high speed centrifugal compressors over the last 20 years. The first reported measurements were obtained by Eckardt (1976) using a Laser-2-Focus Velocimeter. Since then, several other researchers ( Adler and Levy, 1979; Eckardt, 1979; Krain, 1981, 1987; Ahmed and Elder, 1990; Pak et al., 1993; Krain et al., 1995) have used laser anemometers to measure the flow fields within high-speed centrifugal impellers configured with both vaned and vaneless diffusers. Hathaway et al. (1993) reported results from a study in a large low-speed compressor.

In the previous studies, a three-dimensional flow field has been observed in the impeller. The measured flows have been characterized by a region of fluid with low through-flow velocity which is first observed at various meridional and pitchwise locations. This region of low velocity fluid has generally been attributed to a separation initiated by blade and shroud curvature. At the impeller discharge, the flow profile ranges from a jet-wake type flow to a fairly uniform flow as reported by Adler and Levy (1979). The radially ending impellers 
had a discharge profile resembling the jet-wake, whereas the backswept impellers demonstrated a more uniform profile. The depth and location of the wake zone appears to have been modified by the amount of blade backsweep that was applied at the impeller exit.

Hathaway et al. (1993) obtained detailed measurements of the secondary flow fields in a large-low-speed impeller and compared them to the results of a 3D Navier-Stokes simulation using the BTOB3D code (Dawes, 1988). This work suggested that the origin of the low momentum fluid may lie in a vortex which is formed by the interaction of a tip clearance jet with the centrifuged suction surface boundary layer. The vortex first migrates toward the pressure surface and then toward the suction surface. Krain (1987) showed that the downstream regions of low momentum fluid have the characteristics of a vortex flow.

The purpose of the work reported herein was two-fold. First, to obtain a detailed survey of the flow fields in a high speed centrifugal impeller with splitters so as to obtain a data base for validation of the CFD codes that can analyze such geometries. Second, to see if evidence of the vortex initiation identified in the large low-speed compressor could also be found in a smaller high-speed machine.

The impeller used in this study was configured with both vaneless and vaned diffusers. The overall performance of each configuration is presented. Laser surveys were completed in each configuration, but only those obtained in the impeller when it was configured with the vaneless diffuser are presented here. To validate the laser measurements, velocity profiles calculated from total pressure measurements in the vaneless diffuser are presented and compared to those measured using laser anemometry. The measurements are supported further by a BTOB3D code (Dawes, 1988) analysis which predicts a flow field that is similar to the one that was measured and shows the origin of the flow features that were observed.

\section{TEST COMPRESSOR}

The test compressor is a Allison Engine Company design that was scaled up to a flow size of $4.54 \mathrm{~kg} / \mathrm{s}(10 \mathrm{lbm} / \mathrm{s})$ from the original size of $1.66 \mathrm{~kg} / \mathrm{s}(3.655 \mathrm{lbm} / \mathrm{s})$. Complete aerodynamic and mechanical design descriptions, including impeller and diffuser geometries, are given by McKain and Holbrook (1982).

The stage (impeller with vaned diffuser) was designed to produce a pressure ratio of $4: 1$ at the design mass flow. The standard day corrected speed for the design flow condition is $21,789 \mathrm{rev} / \mathrm{min}$ with an exit tip speed of $492 \mathrm{~m} / \mathrm{s}(1615 \mathrm{ft} / \mathrm{s})$. The inlet relative Mach numbers on the suction surface range from 0.9 at the tip to 0.45 at the hub. The impeller contains 15 main blades with 15 splitter blades and has 50 degrees of backsweep from radial at the discharge. The splitter blade leading edge, located at 30 percent of main blade chord, is offset slightly toward the main blade suction surface in order to produce an even flow split. Both the main blades and splitter blades are formed from quasi-normal straight-line elements between the hub and tip. The inlet tip diameter is $210 \mathrm{~mm}$ (8.264 in) and the inlet blade height is $64 \mathrm{~mm}$ (2.501 in). The exit diameter is $431 \mathrm{~mm}$ (16.986 in) and the exit blade height is $17 \mathrm{~mm}$ (0.671 in). All dimensions are for hot conditions at 100 percent of design speed.

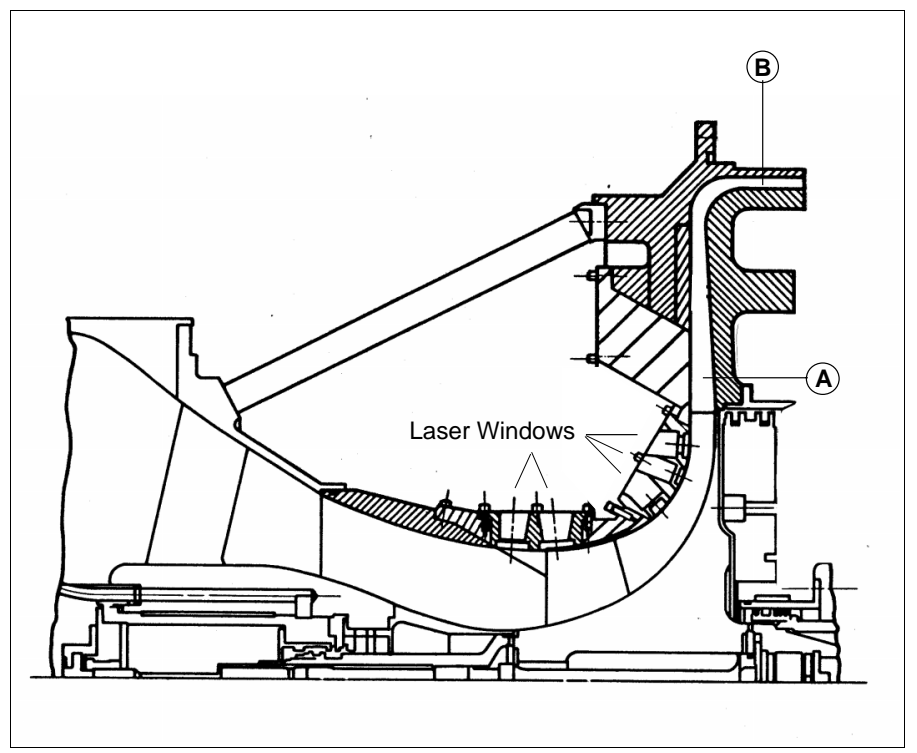

Figure 1: Centrifugal Compressor Flow Path With Laser Windows.

A test-rig cross section showing the flow path through the impeller and vaneless diffuser can be seen in Figure 1. For the impeller-with-vaneless-diffuser configuration, pressure and temperature rakes were located at measurement station $\mathrm{A}$ which was at a radius ratio of 1.18. When the vaned diffuser was installed (stage configuration) rakes at measurement station $\mathrm{B}$ were used.

The five laser windows shown in Figure 1 are from one of four interchangeable window sets. By using various combinations of windows from each set, it was possible to obtain nearly full optical coverage of the flow path through the impeller and vaneless diffuser.

The test facility used for both performance measurements and laser anemometer surveys is an open loop facility with variable inlet and exhaust pressure control. It can accommodate both axial and centrifugal compressors in a wide range of flow sizes and pressure ratios. A complete description of the facility is given by Brokopp and Gronski (1992).

\section{COMPRESSOR PERFORMANCE}

Aerodynamic performance maps of the stage and impeller-withvaneless-diffuser configurations are shown in Figures 2 and 3, respectively. Both performance maps were obtained while the impeller was running with a tip clearance distribution of $0.1524 \mathrm{~mm}(0.006$ inch) near the leading edge, $0.61 \mathrm{~mm}(0.024 \mathrm{inch})$ near mid-chord, and $0.203 \mathrm{~mm}$ (0.008 inch) near the exit.

Stage performance is based upon measurements of total temperature and total pressure that were obtained from fourteen three and four element rakes spaced evenly at measurement station B (see Fig. 1). These were compared to measurements taken upstream of the impeller inlet in the plenum tank. The flow rate was varied between choke and near surge at each speed using a downstream throttle valve. The diffuser controlled the choke and surge mass flows at all speeds. The lowest flow rate shown on each speed line in Figure 2 is the last stable operating point that could be measured. 

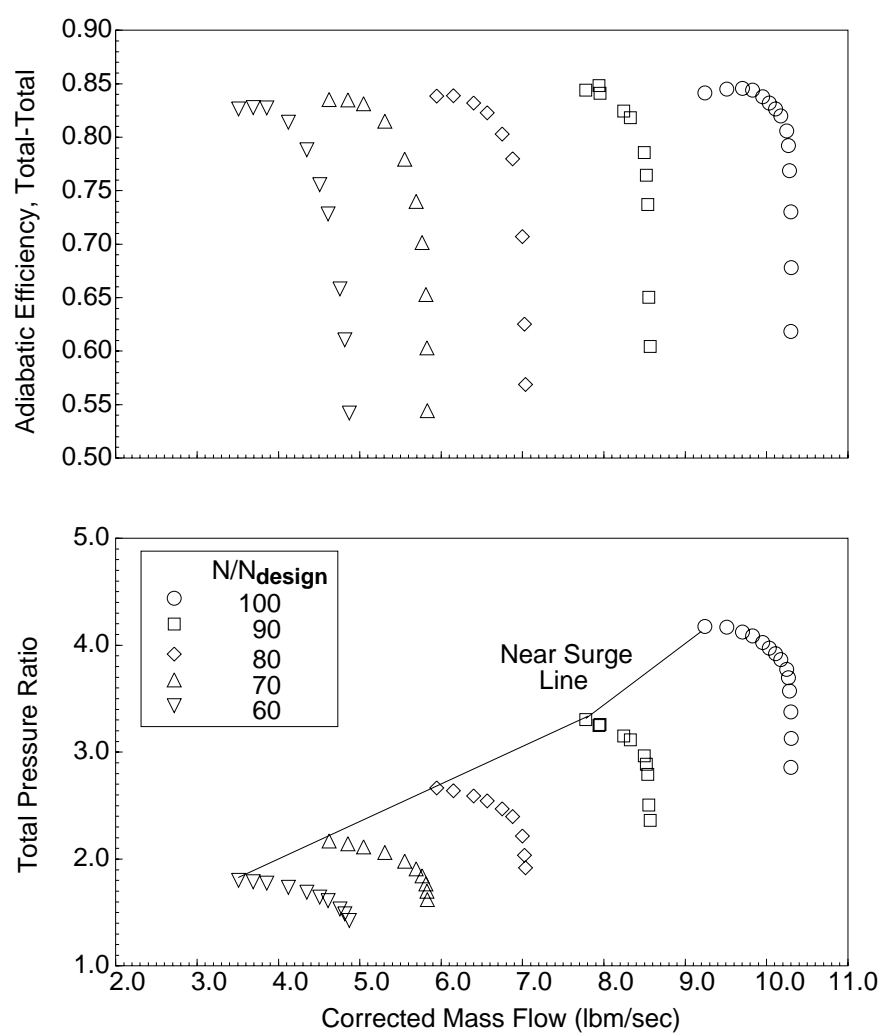

Figure 2: Performance Map Of 4:1 Pressure Ratio Stage

At design speed, a stage total-total peak efficiency of 0.846 was measured at a mass flow of $4.39 \mathrm{~kg} / \mathrm{s}(9.70 \mathrm{lbm} / \mathrm{sec})$. At the design flow rate and speed, a total-total efficiency of 0.832 was obtained for a total pressure ratio of 3.97. Variable air properties were used in the efficiency calculation. The Mach number at the measurement plane was low at 0.14 , so the measured efficiency compares favorably to the 0.830 total-static efficiency predicted by McKain and Holbrook (1992) for the scaled stage.

Impeller-with-vaneless-diffuser performance is shown in Figure 3. The design operating point, which is also the operating point used for laser surveys, is highlighted in the figure. Total temperature and pressure were determined from ten evenly spaced three and four element rakes located in the vaneless diffuser at a radius ratio of 1.18 (location A in Figure 1). The flow range at each speed was greater due to the absence of the vaned diffuser. Because of the closer proximity of the measurement plane to the impeller, higher pressures and efficiencies were measured at all speeds.

At design speed, a peak efficiency of 0.867 occurred at the design mass flow rate. As speed was reduced to 70 percent of design, peak efficiency increased to 0.910 . At 60 percent speed the peak efficiency decreased to 0.897 .
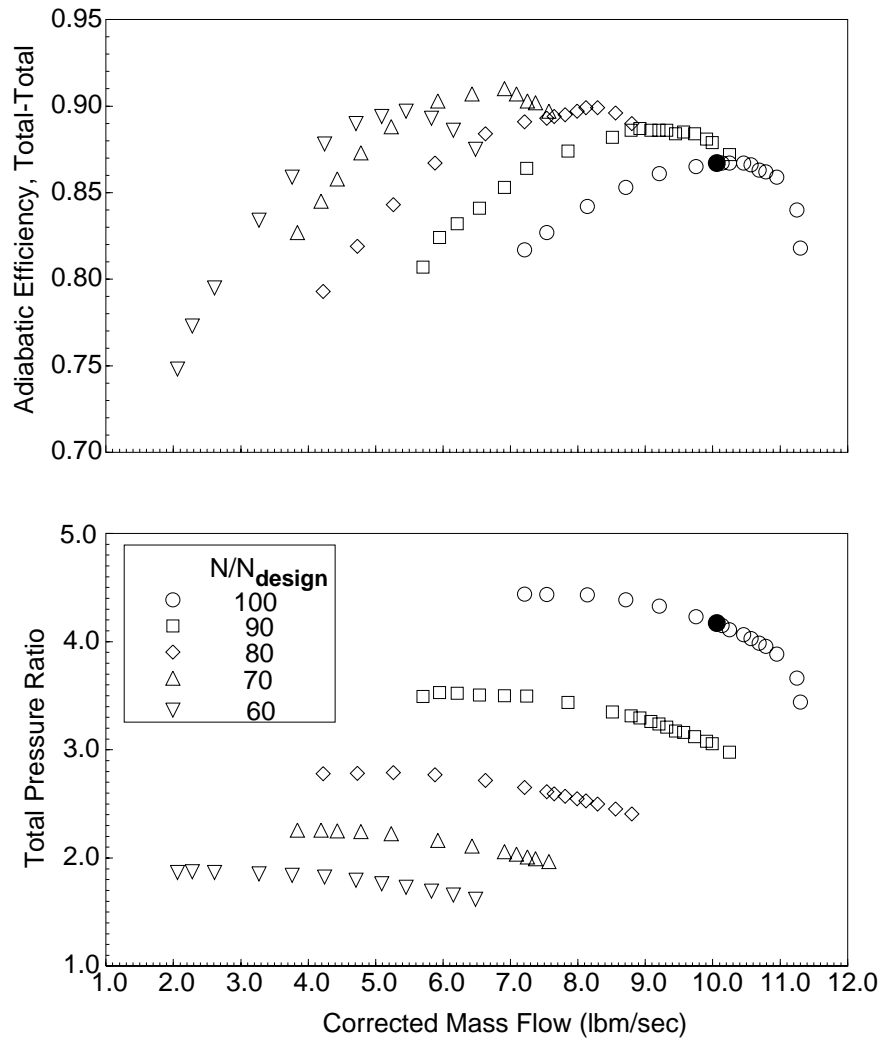

Figure 3: Performance Map Of 4:1 Pressure Ratio Impeller With Vaneless Diffuser

\section{LASER ANEMOMETER MEASUREMENT TECHNIQUE}

\section{General Description}

A single component laser-doppler anemometer operating in the back-scatter mode without frequency shifting was used to obtain flow field velocity measurements. A high-frequency tracking shaft angle encoder was used to divide the circumference of the rotor into 3000 individual bins. The circumferential position of the rotor was recorded with each velocity measurement. Each of the 15 main blade passages on the rotor was divided into 200 bins $\left(\mathrm{N}_{\mathrm{cpp}}=200\right)$ giving a pitchwise resolution of 0.5 percent of main blade pitch. Fiber optic probes were used to track blade passing so that the shaft angle encoder frequency could be reset after each revolution. The encoder count at the end of a revolution was compared to 3000 . If the difference was greater than 20 counts, all data from the revolution were discarded immediately. In the retained data, 77 percent of the revolutions had a difference of zero counts and 98 percent were within 5 counts of 3000 . The basic operating principles of this type of system are described by Strazisar (1986).

Figure 4 shows the measurement locations in the impeller and vaneless diffuser. Measurements from the numbered locations will be presented herein. The spanwise survey lines are "quasi-orthogonal" or nearly normal to the hub and shroud contours. Control of the viewing angle, in the plane of Figure 4, was accomplished by mounting the final beam projection mirror on a goniometric cradle. 


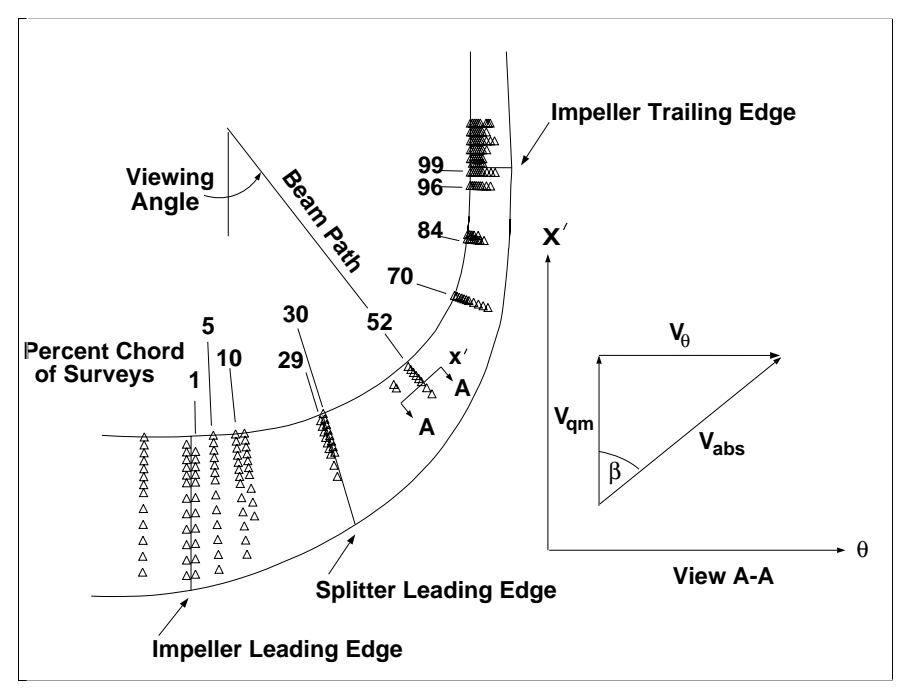

Figure 4: Laser Survey Locations in 4:1 Centrifugal Compressor

Measurements were obtained through a series of windows located in interchangeable plugs in the compressor shroud. Flat windows were used to eliminate the lensing effects which arise from curved windows. The window sizes were kept small to minimize the local clearance which arises from the mismatch between the curved shroud and the flat windows.

The facility was seeded by atomizing a liquid dispersion of Alumina (Aluminum-oxide) powder at the entrance to the plenum tank, far upstream of the measurement locations. The powder was suspended in 100 percent pure ethanol. The electric charge on the surface of the Alumina particles in solution was controlled to prevent particle agglomeration. Surface charge control was achieved by adjusting the $\mathrm{pH}$ of the ethanol-alumina solution using small amounts of $\mathrm{HCl}$ as described by Wernet and Wernet (1994). The seed solution was injected into the plenum tank through air actuated spray nozzles which produced an aerosol. The ethanol component evaporated completely while in the plenum tank leaving only Alumina particles to enter the compressor.

The Alumina powder used in this investigation had a specific gravity of 3.96 and a mean particle size of $0.7 \pm 0.2 \mu \mathrm{m}$. To gage the effect of the relatively high specific gravity of the Alumina powder on velocity measurement accuracy, a back-to-back test was done in a transonic fan using both Alumina and PSL (poly-styrene-latex) particles. The PSL used in the comparison had a mean particle size of $0.5 \mu \mathrm{m}$ and a specific gravity of 1.05 . The results obtained with each seed material were nearly identical with the only difference occurring across the shock. Since the flow fields in the current investigation were subsonic throughout, there were no velocity gradients severe enough to effect the accuracy of velocities measured with the Alumina seed material.

\section{Velocity Determination}

The quasi-meridional survey planes containing the data presented herein are planes that are normal to the plane of Figure 4 and lie along the spanwise survey direction shown at each chordwise location. The laser anemometer acquired velocity measurements in a measurement plane that was orthogonal to both the spanwise survey direction and the plane of Figure 4. A rotating beam separation prism was used to rotate the laser anemometer fringe pattern in the measurement plane. This permitted successive measurements of several components of the flow vector in that plane. Components of the absolute velocity measurements were recorded at angles of 0 and \pm 15 degrees away from the absolute flow angle that was estimated for flows in the measurement plane. Spanwise velocities could not be measured.

For each probe volume orientation, 100,000 velocity measurements were typically collected. Data collected over the entire rotor circumference were first ensemble averaged into a single blade passage. The resultant flow vector $\left(\mathrm{V}_{\mathrm{abs}}\right.$ and $\left.\beta\right)$ in the measurement plane was then determined for each measurement bin across the pitch by fitting the ensemble-averaged component velocities measured at the three orientation angles to a cosine function. A non-linear least squares technique was used to perform the fit.

To calculate quasi-meridional velocities $\left(\mathrm{V}_{\mathrm{qm}}\right)$ the absolute velocity at each measurement location was multiplied by the cosine of the absolute flow angle measured at the same point. The pitchwise profiles of quasi-meridional velocities were then smoothed using a five point box-car averaging technique. Equation (1) shows the calculation of $\mathrm{V}_{\mathrm{qm}}$ and the smoothing technique.

$$
V_{q m}(i)=\frac{\sum_{j=i-2}^{i+2} V_{a b s}(j) * \cos (\beta(j))}{5}, \quad i=3, N_{c p p}-2
$$

\section{Measurement Uncertainty}

The component velocities, measurement angles, and component velocity error estimates were used in the least squares fitting procedure to determine the velocity vector magnitude and flow angle at each pitchwise location. The least squares procedure computes the uncertainty estimates of the fitted parameters (velocity and flow angle) based on the sum of the squared residuals of the fit to the data, the number of degrees of freedom in the system and the value of the parameter element in the covariant matrix (Wolberg, 1967).

The number of component velocity measurements obtained at each fringe pattern orientation were not distributed evenly across a passage. More measurements were obtained at the center of the passage than near the blade surfaces. The uncertainty estimate returned by the least squares procedure contains the effect of flow unsteadiness and blade-to-blade geometry variations as well as the effect of random errors in measurement technique.

Plots of the uncertainty estimate from the least squares procedure were examined at each measurement plane. The uncertainty in resultant velocities ranged from less than $2 \%$ in the center of a passage to $30 \%$ or more near the tip and blade surfaces. However, the regions of high uncertainty coincide with areas where one would expect the flow unsteadiness to also be high. Since the uncertainty 
estimate is low in regions where low unsteadiness is expected, it is assumed that measurement uncertainty due to technique is less than $2 \%$.

Figure 5 shows a comparison of laser measurements to the absolute velocities determined from total pressure measurements taken in the vaneless diffuser at a radius ratio of 1.10 which is slightly upstream of rake location $\mathrm{A}$ in Figure 1. The total pressure measurements were made using a probe which was fully immersed in the diffuser passage for the entire survey. As the survey progressed, the probe traveled deeper into a pocket in the diffuser hub. With this arrangement, the blockage created by the probe was constant over the entire span of the survey. The static pressures needed for the velocity calculation were measured on the vaneless diffuser hub and shroud at the radius of the probe. A linear distribution of static pressure across the passage was assumed in making the velocity calculations.

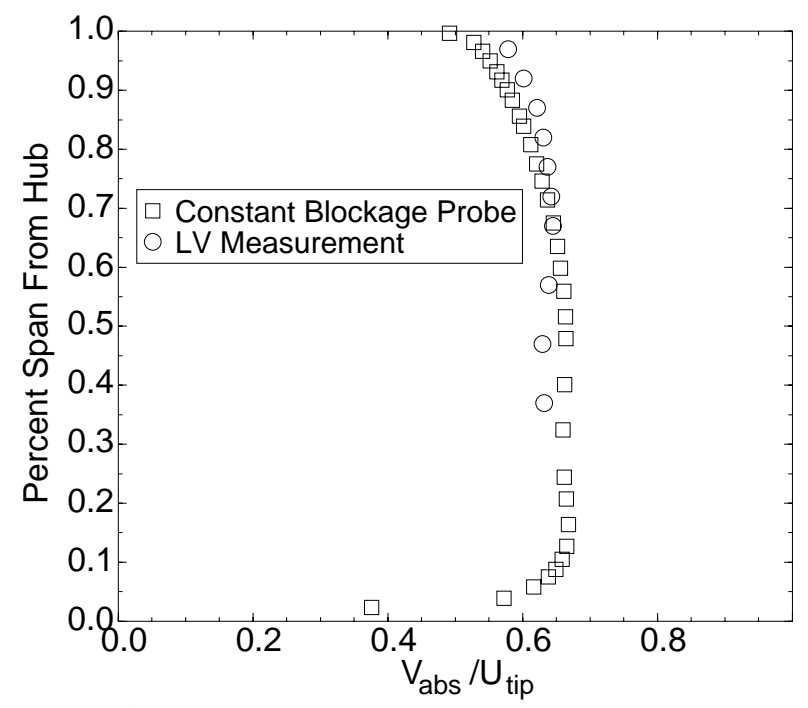

Figure 5: Comparison of velocities measured in the vaneless diffuser using LDV to those calculated from total pressure measurements.

\section{COMPUTATIONAL ANALYSIS}

The computational results for the flow field were obtained using the Reynolds-averaged Navier-Stokes code developed by Dawes (1988). The code solves the equations of motion in cylindrical coordinates in integral conservation form using six-sided control volumes formed by a simple H-mesh. The basic algorithm as described by Dawes (1988) is similar to a two-step Runge-Kutta method plus residual smoothing. A combined second and fourth derivative artificial viscosity model with pressure gradient switching is used to eliminate spurious "wiggles" and to control shock capturing. The eddy viscosity is obtained using the Baldwin-Lomax (1970) mixing length model. Tip clearance is handled by gradually decreasing the thickness of the blade to zero at the blade tip and enforcing periodicity in the tip gap.

Grid generation was done using a NASA-developed code which accounts for the splitter blades and provides good flexibility in distribution of the grid points. Spacing of the grid points is by geometric expansion with a maximum expansion value limited by the grid code to 1.3. Although expansion factors were generally much less than 1.3 , values of 1.3 at the impeller inlet and 1.17 at the exit were used in order to define the tip clearance distribution. For the analysis presented herein 107 grid points were used in the streamwise direction ( $\mathrm{J}$ direction) with the main blade leading edge at $\mathrm{J}=26$, the splitter blade leading edge at $\mathrm{J}=52$, and the trailing edge of both at $\mathrm{J}=88$. Grid points were clustered around the main and splitter blade leading edges. The trailing edge was tapered to zero thickness over two grid points. Grid spacing in the streamwise direction varied from about $0.3 \%$ of chord near the leading edges to $2.6 \%$ between the main and splitter blade leading edges, to nearly $5 \%$ at the splitter mid-chord. In the pitchwise direction 45 grid points were used with an equal number for each splitter channel. In the spanwise direction 47 points were used with 4 cell volumes in the clearance gap.

The grid code was used to incorporate the measured distribution of tip clearance, which varied from the impeller inlet to exit, into the grid. The Dawes code assumes a tip clearance that is a constant percent of blade span from inlet to outlet, therefore, it was modified to read the grid that was generated to match the measured tip clearance distribution. The full tip clearance as noted under "Compressor Performance" was used in the analysis.

The Dawes code automatically uses the wall-function approximation for the wall shear stress when the cell-center nearest a wall lies farther from the surface than a $\mathrm{Y}+$ of 10 . For the solution presented herein, the average $\mathrm{Y}+$ values for the near-wall cell-centers of the grid were 19 for the hub, 32 for the shroud, and approximately 60-75 for all blade surfaces. The wall-function was therefore used at nearly all grid points.

A number of grid parametric variations were done to investigate the grid sensitivity of the solution. The effect of grid density was checked by increasing the pitchwise number of grid points to 69 while maintaining the near-wall spacing, which reduced the grid spacing by $50 \%$ at mid-pitch. The number of grid points in the spanwise direction was increased to 77 while maintaining the near-wall spacing, which reduced the spanwise grid spacing by $50 \%$. These changes in the grid had a relatively small effect on the solutions.

The sensitivity of the solution to the treatment of the tip clearance was checked by generating a grid with 0.6 times the physical clearance and another grid with the inlet tip clearance doubled. The number of cells in the tip clearance was also doubled from 4 to 8 . These changes had a small effect on the solution and no effect on the conclusions reached in this work. The amount of clearance flow that crossed the blade tips was calculated to be $7.8 \%$ of the inlet mass flow for the main blade and 5.8\% for the splitter blade using the solution generated with the baseline grid.

\section{RESULTS AND DISCUSSION}

\section{Inlet Region}

The operating point selected for all laser anemometer surveys and computations reported here was the design mass flow rate of 4.54 $\mathrm{kg} / \mathrm{s} \quad(10 \mathrm{lbm} / \mathrm{s})$ with the previously described tip clearance distribution. This point is highlighted in Figure 3. 
The normalized through-flow velocity distribution, $\mathrm{V}_{\mathrm{qm}} / \mathrm{U}_{\text {tip }}$, measured at $1 \%$ of main blade chord is shown in a carpet plot format in Figure 6. Since velocity magnitudes are difficult to determine from a three dimensional plot, a table is included to give a snapshot of the velocity magnitudes. Spans are listed from tip to hub, where 100 percent span is located at the blade tip. At each span, the normalized through-flow velocity is reported at 25, 50 and 75 percent blade gap across the passage. The velocity profiles at each spanwise location contain a small "+" at points where the velocity magnitudes are reported. The velocity distribution shown in Figure 6 increases toward the suction surface in a linear fashion and is similar to inducer velocity profiles that were reported by Eckardt (1976), Krain (1987), and Hathaway, et al. (1993).

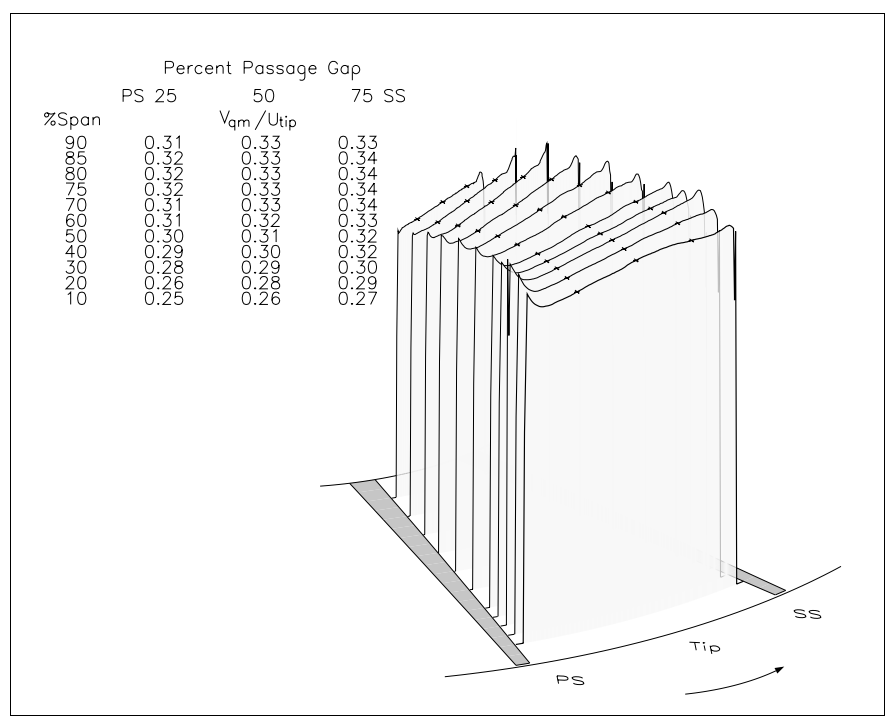

Figure 6: Distribution of through-flow velocities measured on a plane located at $1 \%$ of main blade chord

Figures 7 - 9 show carpet plots of data taken at 5\%, 10\%, and $29 \%$ of main blade chord, respectively. All plots show the typical increase in velocity from pressure surface to suction surface with some indication of low momentum flow near the shroud. This low momentum region is first detected near the suction side of the channel at $5 \%$ chord and $100 \%$ span. At $10 \%$ chord the velocity in this region has decreased considerably relative to the velocity at $95 \%$ span. The plane at $29 \%$ chord does not show any evidence of the low momentum region. Data was not acquired beyond $95 \%$ span on this plane, and the low momentum region near the tip may well lie outboard of $95 \%$ span. The flow field at $29 \%$ chord does, however, show evidence of the potential field of the splitter leading edge located at $30 \%$ chord.

Data acquired downstream of the splitter leading edge will be presented in the form of cross-passage contour plots of $\mathrm{V}_{\mathrm{qm}} / \mathrm{U}_{\text {tip }}$ since contour plots illustrate the migration of low velocity regions better than carpet plots. In the discussion of these results, the passage adjacent to the main blade pressure surface will be referred to as the "pressure side" passage. The "suction side passage" will refer to the passage adjacent to the main blade suction surface.

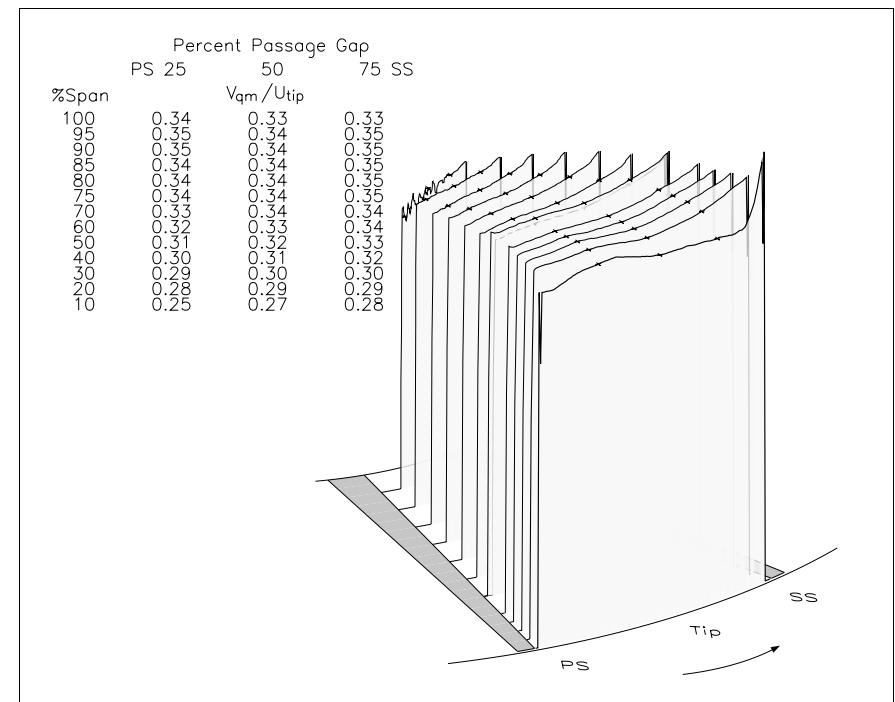

Figure 7: Distribution of through-flow velocities measured on a plane located at $5 \%$ of main blade chord

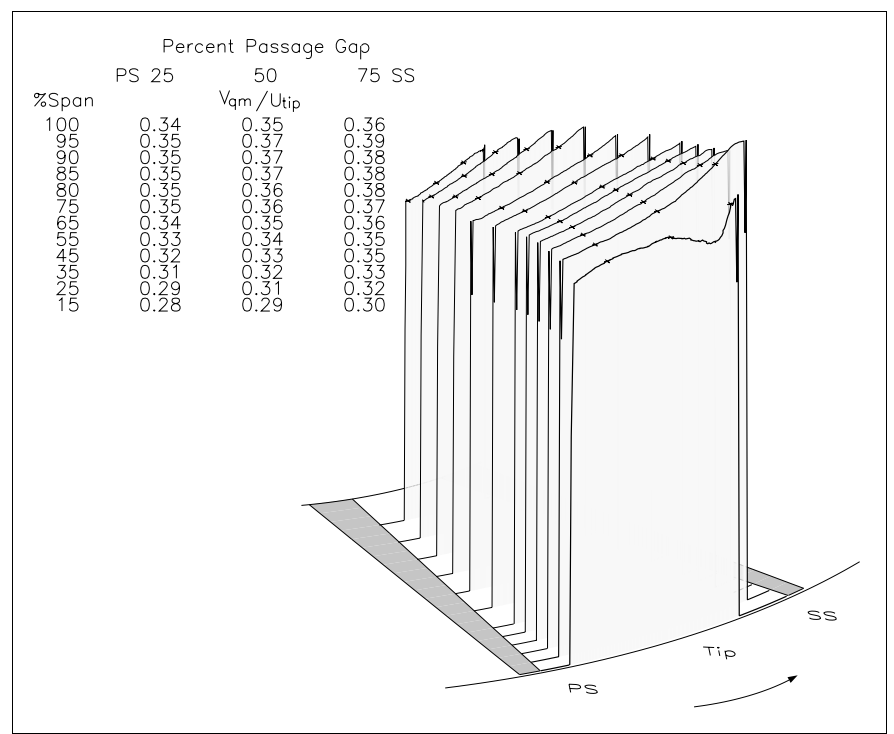

Figure 8: Distribution of through-flow velocities measured on a plane located at $10 \%$ of main blade chord

Carpet and contour plots of the through-flow velocity distribution at the splitter leading edge plane at $30 \%$ of main blade chord are shown in Figures 10 and 11. The carpet plot shows the obvious presence of the splitter but also indicates a large region of low momentum flow near the tip on either side of the splitter leading edge. This is shown more clearly in the contour plot, where the loading on the splitter leading edge can be seen at all spans. Low momentum regions occur around the splitter leading edge and near the main blade pressure surface. The latter results from deceleration of the flow in the streamwise direction along the pressure surface due to the main blade loading. 


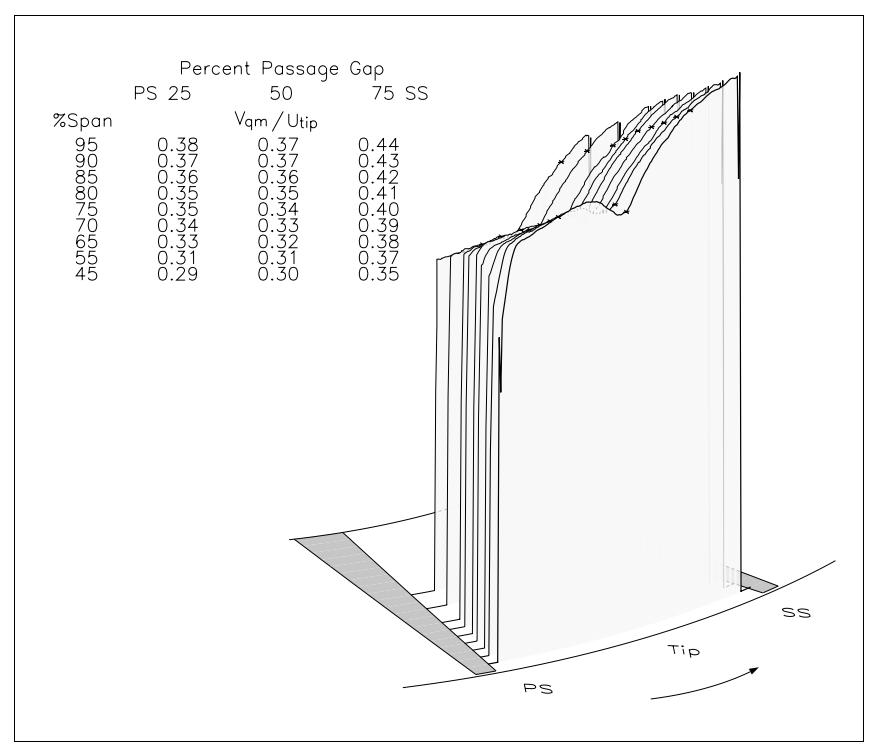

Figure 9: Distribution of through-flow velocities measured on a plane located at $29 \%$ of main blade chord

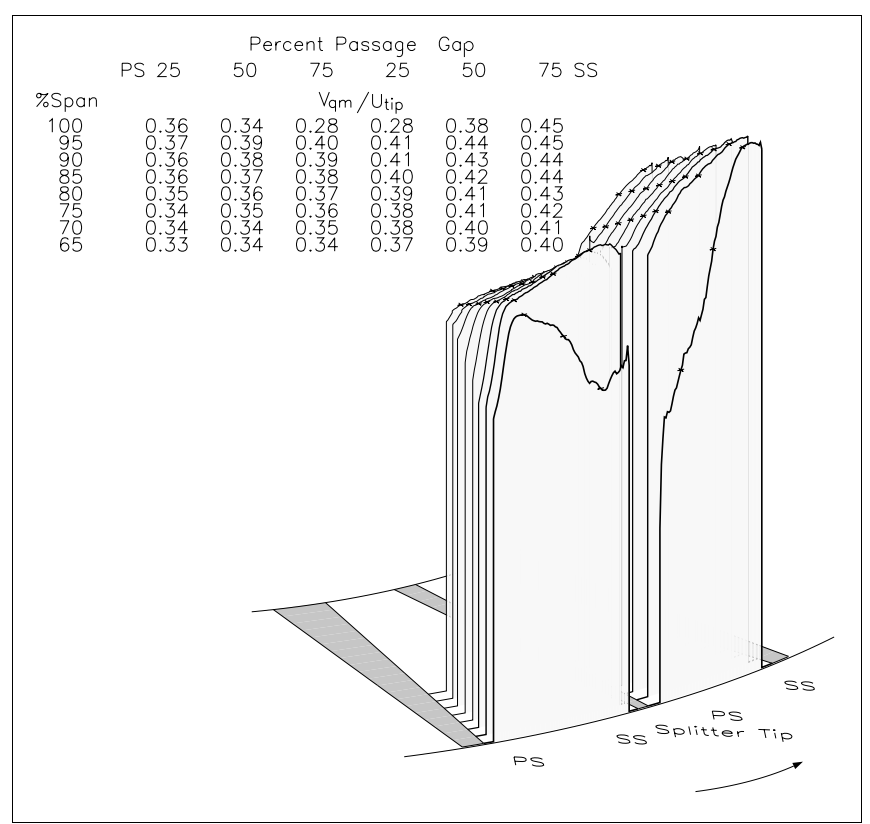

Figure 10: Distribution of through-flow velocities on a plane located near the splitter-blade leading edge $(30 \%$ of main-blade chord)

A clearer picture of the flow development upstream of the splitter leading edge can be obtained using the simulation generated with the Dawes code. Figure 11a shows the predicted distribution of $\mathrm{V}_{\mathrm{qm}} / \mathrm{U}_{\text {tip }}$ on cross-sectional planes at 5, 10 and $30 \%$ chord, properly oriented in the impeller channel. The calculations at these three planes show qualitatively the same information as did the measured data. The predicted momentum deficit near the blade tip is somewhat more

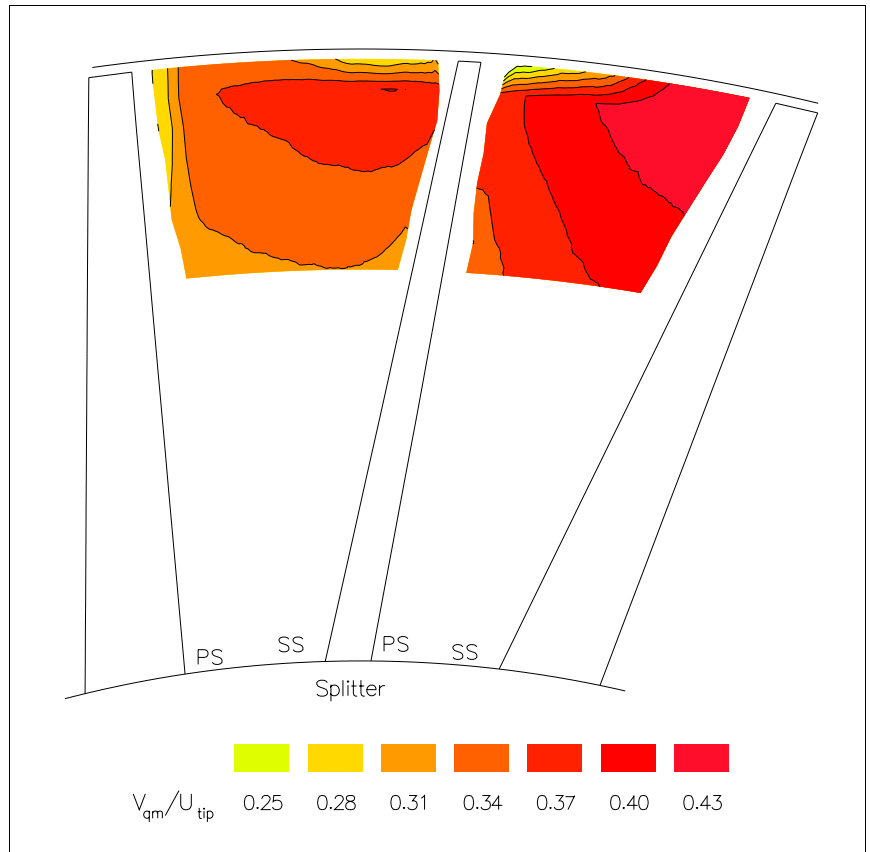

Figure 11: Through-flow velocity contours on a plane located near the splitter-blade leading edge ( $30 \%$ of main blade chord)

shallow and broader at 5\% chord than at $10 \%$ chord (note the velocities at $50 \%$ and $75 \%$ pitch at $100 \%$ span in figures 7 and 8). The tip clearance flow impacts the splitter leading edge as it moves across the main blade channel from the suction side toward the pressure side. Relative velocity vectors, not shown here, were generated on the grid surfaces just above the tip of the blade and were color coded to match the quasi-meridional velocity shown on the cross-sections. These vectors clearly showed the movement of the clearance flow across the channel. Flow tracers released in the tip gap near the suction side of the passage at several percent chord locations are shown in Figure 11a to indicate this general movement. The red trace which was released on the suction surface near the leading edge migrates radially outward to the blade tip where it is entrained by the clearance flow and pushed toward the splitter.

The secondary flow in the inlet is, as might be expected for a subsonic impeller, quite similar to that reported by Hathaway et al. (1993) for a large centrifugal compressor in which quite detailed three-dimensional velocities were measured with a laser anemometer system. The particle tracer studies of the CFD simulation, not shown here, indicate that fluid near the blade and hub solid surfaces is driven toward the shroud by the hub-to-shroud pressure gradient established by the main flow. Once at the shroud this low momentum flow is entrained by the flow leaking over the tip of the blade and carried toward the pressure side of the channel. This was clearly shown in the work of Hathaway et al. with both the measurements and calculations. The only difference in the present work is the presence of the splitter which causes the deficit flow to be unequally distributed in the two channels formed by the splitter blade. 


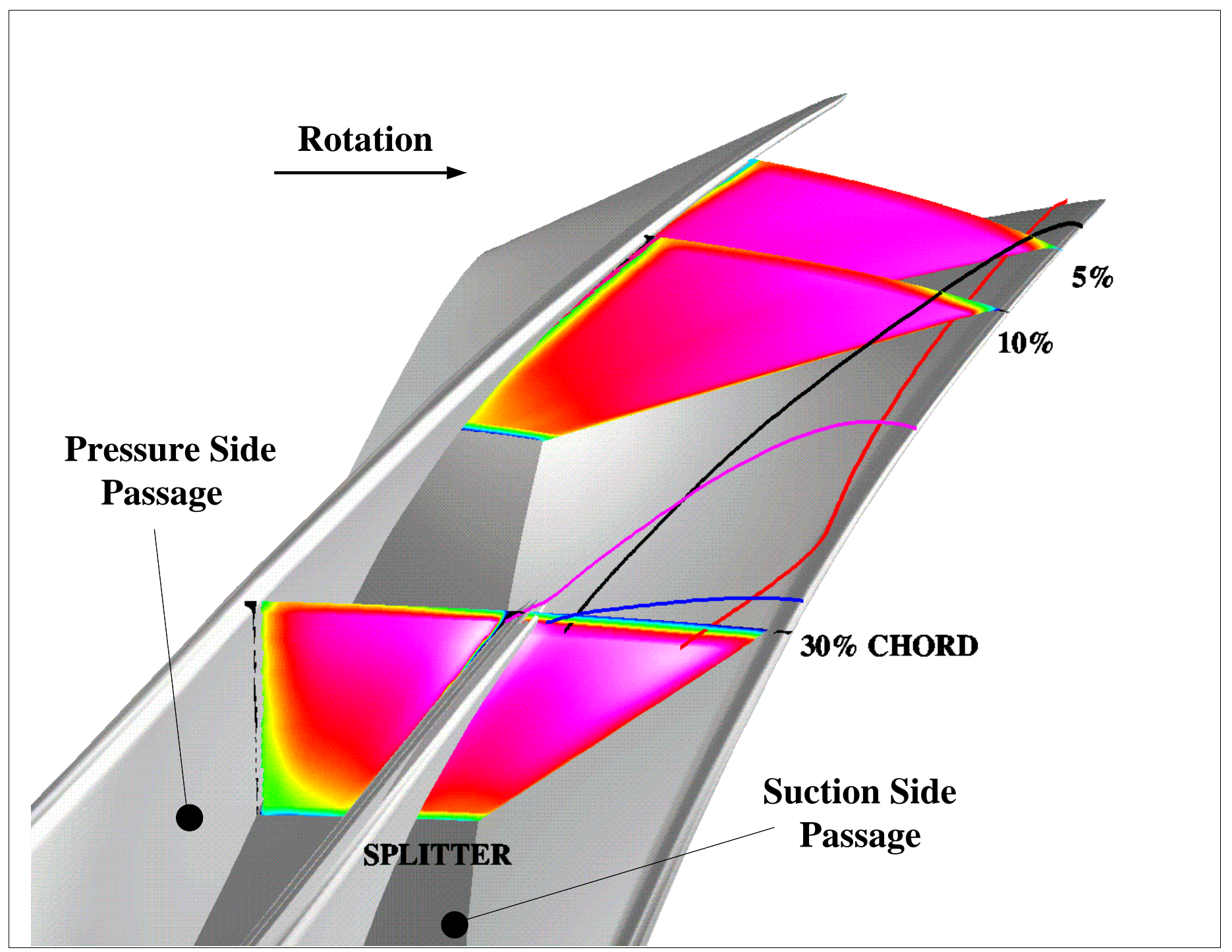

Figure 11a: Predicted distribution of $\mathrm{V}_{\mathrm{qm}} / \mathrm{U}_{\mathrm{tip}}$ at 5,10 and $30 \%$ of main blade chord

\section{Splitter Entry Region}

At $52 \%$ chord, Figure 12, the pitchwise extent of the velocity deficit has increased in both passages. The magnitude and spanwise depth of the deficit region have increased much more in the suction side passage where the depth extends down to $80 \%$ span. The center of this region is nearer the splitter blade pressure surface. Data not shown here, that were collected at $85 \%$ and $90 \%$ spans on a plane at $47 \%$ chord, also indicate the presence of a well developed low velocity region near the splitter blade in the suction side passage. The pitchwise coverage of the deficit has increased in the pressure side passage, while the spanwise depth and magnitude of the velocity gradient have not changed very much. The center of the deficit region appears closer to the center of the passage than it did at $30 \%$ chord, as though it is still moving toward the main-blade pressure surface.

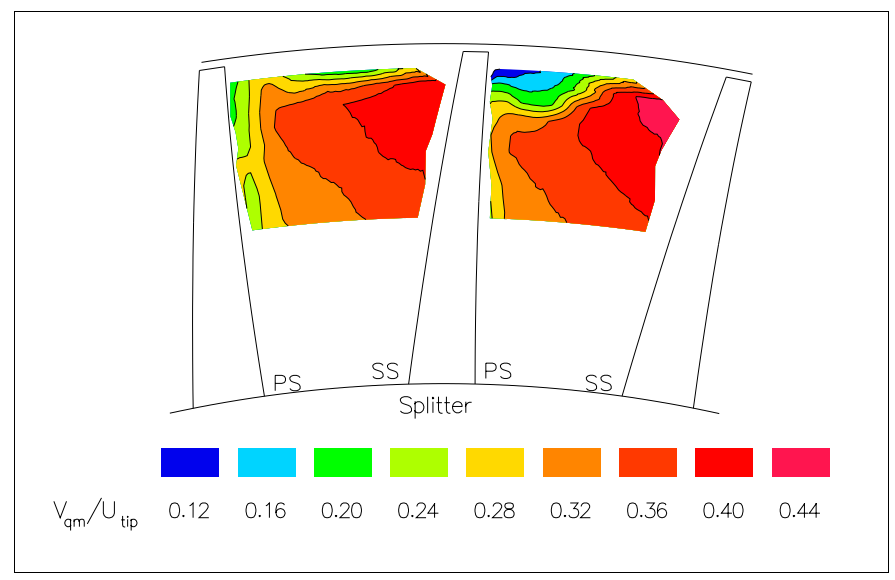

Figure 12: Contours of through-flow velocity measured on a plane located at $52 \%$ of main blade chord 
The large deficit region in the suction side passage at 52\% chord results when the splitter "scrapes up" the tip clearance and near wall flows that have been moving across the main blade channel from the suction surface toward the pressure surface. This process is more clearly seen in Figure 12a which shows flow tracers generated from the CFD solution superimposed on a blade-to-blade plot of the quasimeridional velocity measured with the laser anemometer at $90 \%$ span. The black tracers released in the main blade tip clearance gap from the leading edge to $74 \%$ chord are swept toward the pressure side of the channel. The tracers upstream of the splitter leading edge are continually pushed deeper into the main flow by the leakage flow occurring downstream and are subsequently turned in the streamwise direction by the main flow. This "early" leakage flow is "scraped" by the splitter and forms the low momentum region on the splitter pressure surface as shown in figures 10,11 and 12. As the fluid particles in this leakage flow hit the splitter they are turned down into the main flow to form the deficit in velocity in the suction side passage at $52 \%$ chord, as shown in Figure 12a.
The white tracers in Figure 12a are released along the span near the main blade suction surface at the splitter leading edge plane. These tracers move toward the shroud and are entrained by the cross-channel flow near the shroud. The cyan tracers are released in the tip clearance gap downstream of the splitter leading edge. Some of the fluid marked by both the cyan and white tracers is forced into the deficit region in the suction side passage and some combines with the leakage from the main blade and leaks over the splitter blade and into the deficit region in the pressure side passage. The deficit region in the pressure side passage is not as large as that in the suction side passage because the leakage flow generated from the main blade upstream of the splitter leading edge is primarily contained in the suction side channel. The simulations show the deficit region to be closer to the center of the suction side channel than does the data. According to the simulations, $52 \%$ chord is just downstream of where the low momentum fluid impacts on the splitter blade pressure surface and begins to move back toward the suction surface of the main blade.

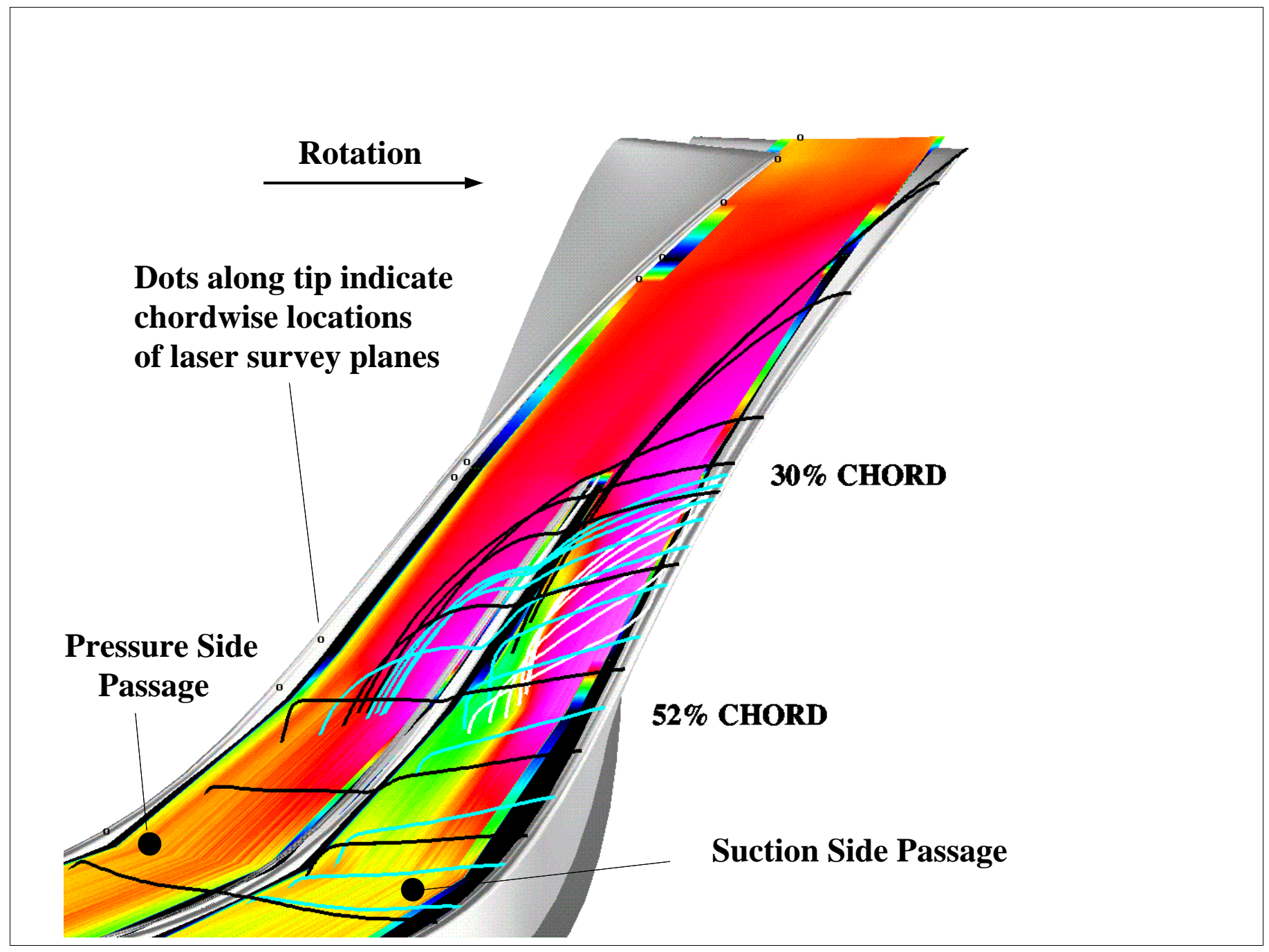

Figure 12a: CFD tracers superimposed on measured through-flow velocity at $90 \%$ span 


\section{Exit Region}

The measured flow field downstream of $70 \%$ chord is presented in Figures 13-15, 17 and 18. The predicted flow field at 70, 84 and 96 percent chord is shown in Figure 16.

By $70 \%$ chord (Figure 13) the shroud deficit region in the suction side passage has moved closer to the suction surface of the main blade and a deficit has also developed in the pressure side passage near the splitter blade suction surface. The low momentum regions near the pressure side of each passage are due to the loading on the main and splitter blades and are comparable in size. By this location, the calculations have begun to deviate more from the data but the general flow pattern is captured (i.e. there is more low momentum fluid accumulated near the shroud for the suction side passage than for the pressure side passage in both the data and the calculations). The calculation, however, indicates that a low momentum "tail" is beginning to form and is being pushed toward mid-span in both passages as shown in Figure 16. That feature is not seen in the data. The velocity deficit for the calculations is greater than that of the data.

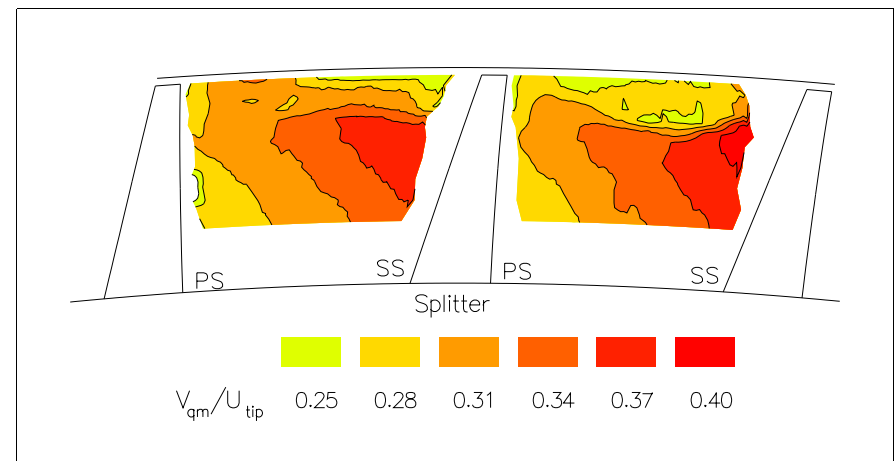

Figure 13: Contours of through-flow velocity measured on a plane located at $70 \%$ of main-blade chord

At $84 \%$ chord, Figure 14, the low velocity region is now accumulating near the suction surface in both passages and is increasing in depth. In the pressure side passage, a low velocity core has moved downward in spanwise position near the splitter blade. This core now contains the lowest through-flow velocity fluid found in either passage. The velocity distribution found at $84 \%$ chord is the opposite of that found farther upstream at 52\% chord (Figure 12) where the suction side passage contained the lowest velocity flow. In the suction side passage at $84 \%$ chord the low velocity region near the main blade suction surface has the same general shape as the region in the pressure side passage but does not contain a well developed core of very low velocity fluid. The low velocity region near the splitter blade in the pressure side channel is quite similar to the low velocity region in the pressure side passage for the calculations. The calculations (Figure 16) show very low velocity fluid near the shroud with the "tail" mentioned at $70 \%$ chord more pronounced and closer to $50 \%$ span. Although, there does not appear to be a "tail" in the suction side passage for the data, with suitable high-lighting of the contours, a faint tail is distinguishable. It is not, however, as pronounced as the one produced by the calculations. Flow tracers released in the calculations in the center of the "tail" of low velocity fluid in the pressure side passage, show that this fluid came mainly from boundary layer fluid on the main blade pressure surface but with some contribution from the migration of boundary layer fluid on the splitter blade suction surface and tip clearance flow over the splitter blade.

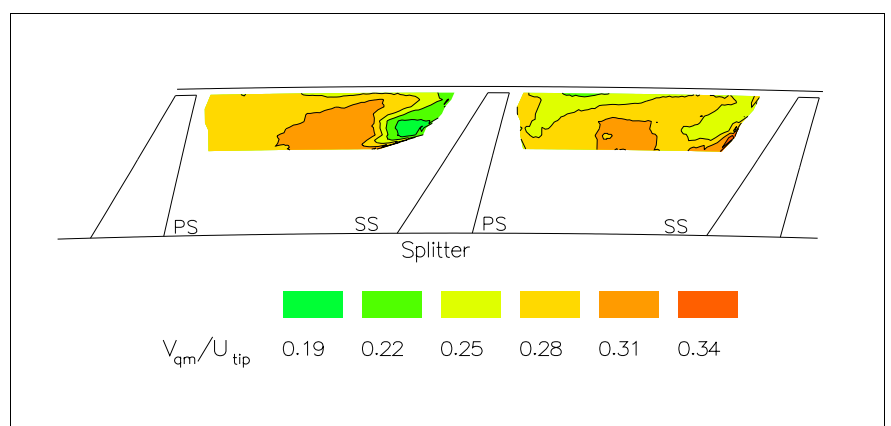

Figure 14: Contours of through-flow velocity measured on a plane located at $84 \%$ of main-blade chord

At $96 \%$ cord, Figure 15, the velocity deficit remains well-developed in the pressure side passage. A large deficit region exists near the shroud from about $50 \%$ pitch to the splitter suction surface and at about $50 \%$ span near the same surface. The deficit in the pressure side passage looks somewhat similar to that produced by the calculations but the velocity magnitudes are different. The flow pattern measured in the suction side channel is similar to that in the pressure side but the velocity gradients are far less.

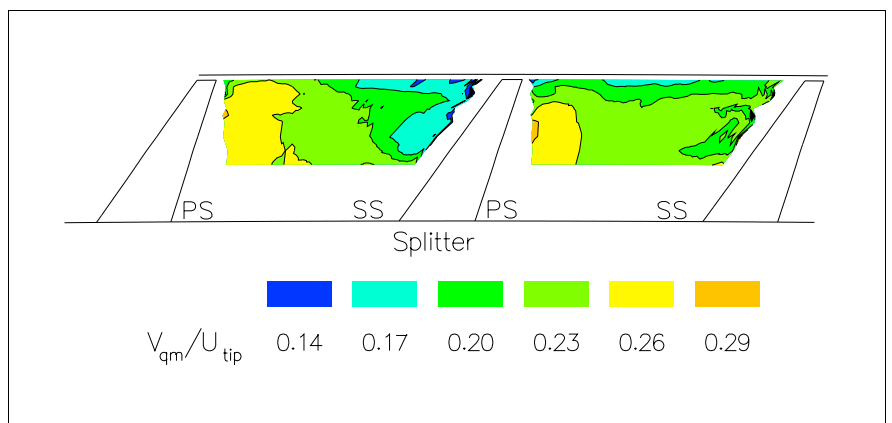

\section{Figure 15: Contours of through-flow velocity measured on a plane located at $96 \%$ of main blade chord}

Based upon the calculations and their agreement with the data we see a similar type of flow in the pressure and suction side passages. Low momentum tip clearance flows and blade viscous layers migrate in the channel and accumulate near the shroud-suction surface in both passages which is consistent with observations by other authors. It is not clear, however, why the deficit region in the pressure side passage is more pronounced than that in the suction side passage. Integration of the calculations to determine the mass flow split in each splitter channel revealed that the flow in the pressure side passage was consistently 0.5 to $1 \%$ greater than that in the suction side passage. 


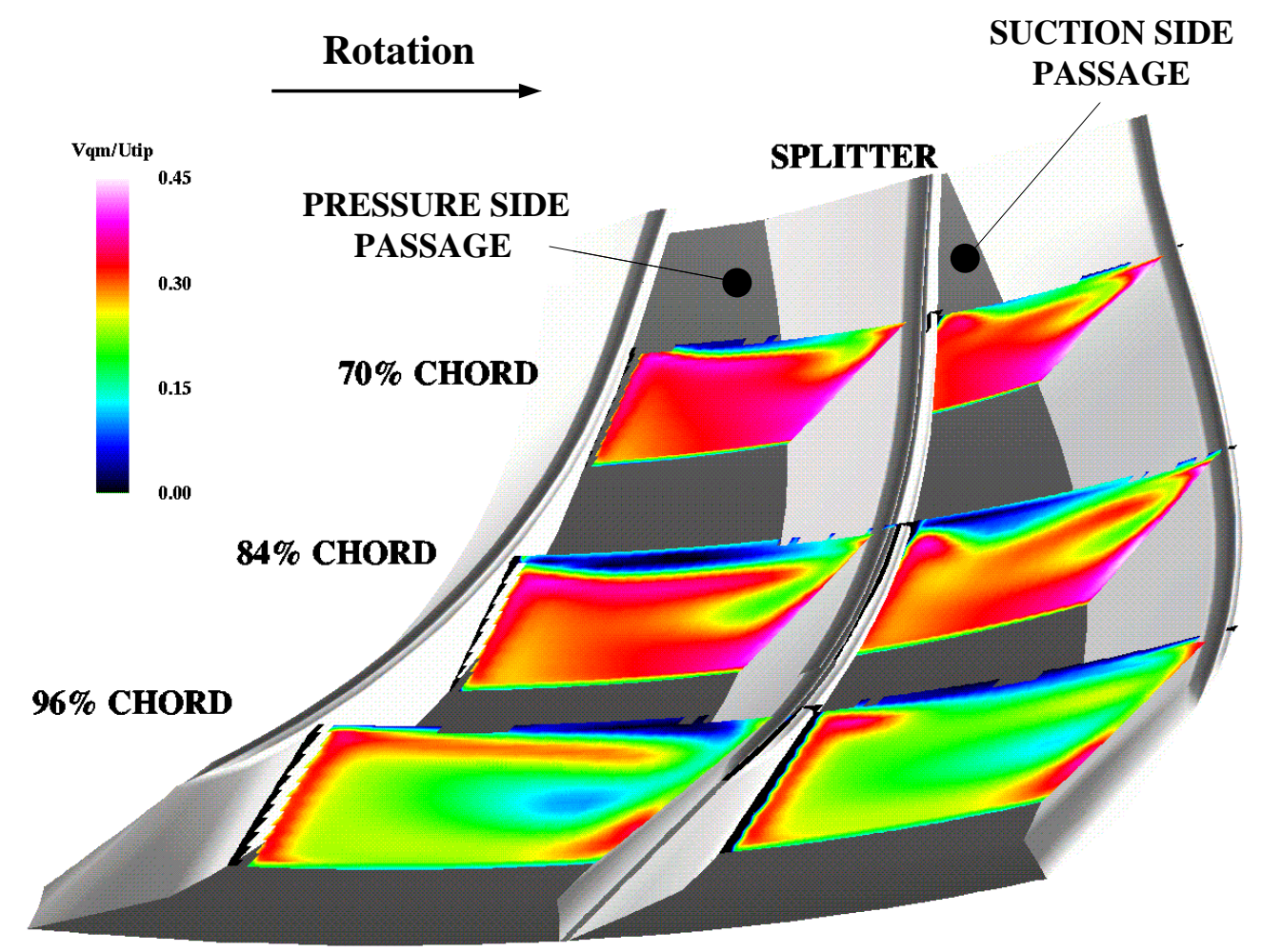

Figure 16: CFD prediction of through-flow velocity at 70, 84 and 96 percent of main blade chord

At $99 \%$ chord, Figure 17, the measured through-flow velocity contours have taken on a more stratified appearance at pitchwise locations that are away from the suction surface in each passage. Pockets of low velocity flow remain centered about a lower span in the region adjacent to each suction surface.

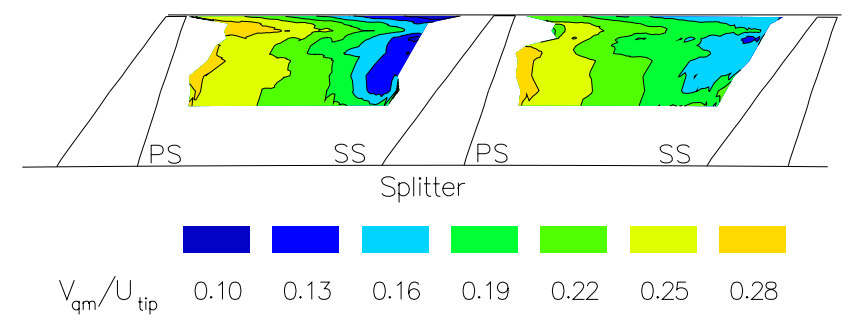

Figure 17: Contours of through-flow velocity measured on a plane located at $99 \%$ of main blade chord

Except for the pockets of low velocity fluid from Figure 17, the profile across each passage near the discharge is somewhat linear across the pitch and does not resemble a traditional jet-wake profile. Figure 18 more clearly shows the through-flow velocity profile at $99 \%$ chord. The low velocity pockets of Figure 17 can not be seen as they

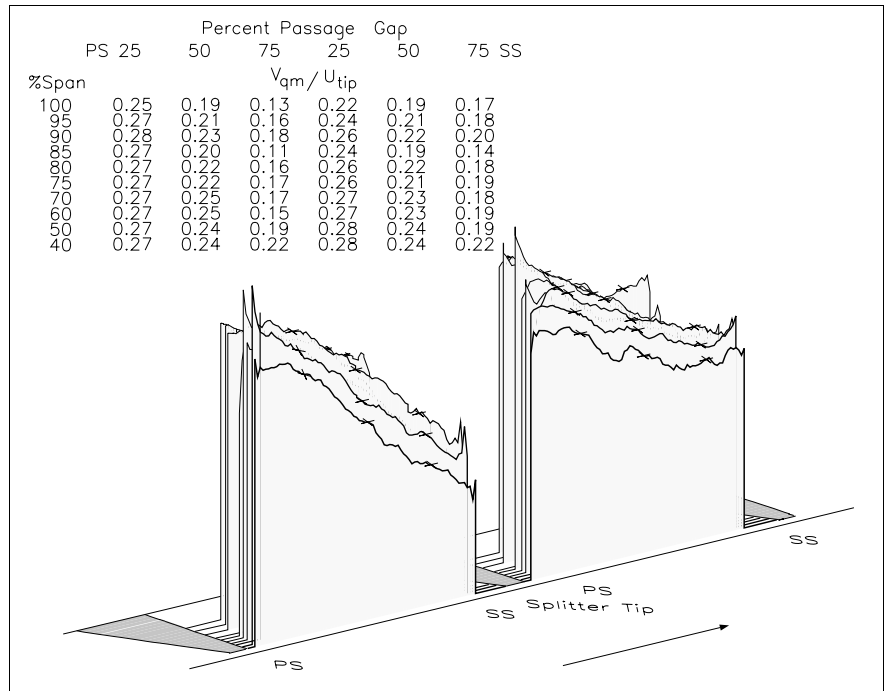

Figure 18: Distribution of through-flow velocities on a plane located at $99 \%$ of main blade chord 
are behind the profiles shown for the outermost spans. In the pressure side passage, the profile is nearly linear across the pitch. The profile of the suction side passage is similar to the discharge profile reported by Krain (1987) for an impeller with 30 degrees of backsweep. The discharge profile of that impeller showed the through-flow velocity increasing toward the hub and less so toward the pressure surface with a slight depression near midpitch.

\section{Wake Decay in the Vaneless Diffuser}

Hathaway et al. (1993) reported wake decay from their large centrifugal compressor tests which indicated that the wake from the blades decays very rapidly such that at radius ratios of 1.04 and 1.06 the pitchwise variation in absolute flow angle is below 10 degrees. In addition they measured the decay of the wake near the shroud where the tip clearance flow formed a second region of low radial momentum fluid. The blade wake fluid near the shroud also decayed very rapidly near the trailing edge; however, the "wake" associated with clearance flow decayed less rapidly as a result of its much lower velocity gradient and, thus, shear stress compared to that in the blade wakes.

In the present investigation spanwise surveys were taken at radius ratios of 1.01, 1.02, 1.04, 1.06, 1.08, and 1.10. The angle variation is shown in Figure 19. The wakes have been shifted in the pitchwise direction to align all of the main blade wakes in the plot. Each trace is referenced to the minimum flow angle, $\beta_{\min }$, for its radius ratio and percent span in order to show the pitchwise variation to which a diffuser vane might be subjected if one were present. The angle variation decreases rapidly to 10 degrees or less by a radius ratio of about 1.04 which is consistent with the value reported by Hathaway for comparable radius ratios. In the present study the tip clearance "wake" is adjacent to the blade wake suction surface and is distinguished from the blade wake at and above $85 \%$ span by a distinct "plateau" in absolute flow angle over about $15 \%$ of main blade pitch at the $100 \%$ percent span location. This is due to the clearance flow accumulating near the blade surfaces at the impeller exit as indicated in Figure 17.

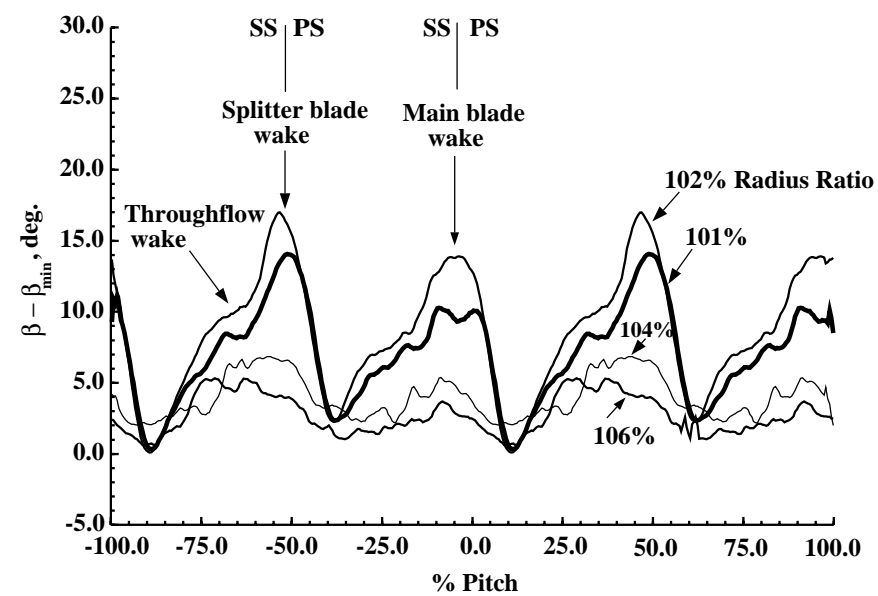

Figure 19: Pitchwise absolute flow-angle difference near 100 percent of diffuser span

\section{CONCLUSIONS}

1) The formation of a through-flow velocity deficit may begin farther upstream than has been previously suggested for high speed impellers. It begins as the inducer suction surface boundary layer migrates toward the blade tip and becomes entrained in the tip clearance flow. The deficit then moves toward the pressure surface.

2) The majority of the initial deficit is trapped and "scraped up" by the splitter blade which causes it to turn down and roll-up in the suction side passage, thereby creating a larger velocity deficit in that passage.

3) Some flow leaks over the splitter blade tip in a manner that is similar to the inducer leakage flow. This flow joins with the portion of the upstream deficit that entered the pressure side passage.

4) The velocity deficits in both passages are eventually driven back toward the suction surface by the cross-passage pressure gradients.

5) The discharge velocity profile of this impeller did not have the characteristics of a jet wake. The profile was similar to discharge profiles reported by others who have tested backswept impellers.

6) The rate of decay of the overall wake region is similar to that which was reported by Hathaway et al. (1993) in a large low-speed impeller.

\section{ACKNOWLEDGMENTS}

The authors would like to acknowledge the contributions of Richard Brokopp, Antonio Zaldana and James Berk for test cell operation; Robert Gronski and Harry Fuller for test cell electronics support; and Wentworth Trevor John for the assistance he provided in setting up and maintaining the laser anemometer system. Without their hard work and dedication the measurements reported herein would not have been completed.

\section{REFERENCES}

Eckardt, D., 1976, "Detailed Flow Investigations Within A High-Speed Centrifugal Compressor Impeller," ASME Journal of Fluids Engineering, Vol. 98, pp. 390-402.

Adler, D., and Levy, T., 1979, "A Laser-Doppler Investigation Of The Flow Inside A Backswept, Closed, Centrifugal Impeller," Journal Mechanical Engineering Science, Vol 21, No. 1, pp. 1-6.

Eckardt, D., 1979, "Flow Field Analysis of Radial and Backswept Centrifugal Impellers - Part I. Flow Measurements Using a Laser Velocimeter," in "Performance Prediction of Centrifugal Pumps and Compressors," Proceedings of the Twenty-fifth Annual International Gas Turbine Conference and Exhibit, ASME, pp. 77-86.

Krain, H., 1981, "A Study on Centrifugal Impeller and Diffuser Flow," Transactions of the ASME, Vol 103, October 1981, pp. 688697. GT-19. 
Ahmed, N., A., and Elder, T., L., 1990, " Flow Investigation in a Small High Speed Impeller Passage Using Laser Anemometry," ASME Paper No. 90-GT-233.

Pak, H., Krain, H., Hoffmann, B., 1993, "Flow Field Analysis in a High Pressure Ratio Centrifugal Compressor," Technology Requirements for Small Gas Turbines, AGARD-CP-537.

Krain, H., Hoffmann, B., Pak, H., 1995, "Aerodynamics of a Centrifugal Compressor Impeller with Transonic Inlet Conditions," ASME Paper No. 95-GT-79.

Hathaway, M., J., Chriss, R., M., Wood, J., R., Strazisar, A., J., 1993, "Experimental and Computational Investigation of the NASA Low-Speed Centrifugal Compressor Flow Field," ASME Journal of Turbomachinery, Vol. 115, pp. 527-542.

Dawes, W., N., 1988, "Development of a 3-D Navier Stokes Solver for Application to all Types of Turbomachinery," ASME Paper No. 88-GT-70.

McKain, T., F., and Holbrook, G., J., 1982, "Coordinates for a High Performance 4:1 Pressure Ratio Centrifugal Compressor," Final Report, NASA Contract NAS 3-23268, (To be published as a NASA Contractor Report).

Brokopp, R., A., and Gronski, R., S., 1992, "Small Engine Components Test Facility Compressor Testing Cell at NASA Lewis Research Center," NASA TM 105685.

Strazisar, A., J., 1986, " Laser Fringe Anemometry For Aero

Engine Components," Advanced Instrumentation for Aero Engine Components, AGARD CP-399.

Wernet, J., H., and Wernet, M., P., 1994, "Stabilized Alumina/Ethanol Colloidal Dispersion for Seeding High Temperature Air Flows," NASA TM 106591.

Wolberg, J., R., 1967, "Prediction Analysis," Van Nostrand Co., New Jersey, pp. 254-266.

Baldwin, B., and Lomax, H., 1970, "Thin Layer Approximation and Algebraic Model for Separated Turbulent Flows," AIAA Paper No. 78-257. 
Public reporting burden for this collection of information is estimated to average 1 hour per response, including the time for reviewing instructions, searching existing data sources, gathering and maintaining the data needed, and completing and reviewing the collection of information. Send comments regarding this burden estimate or any other aspect of this collection of information, including suggestions for reducing this burden, to Washington Headquarters Services, Directorate for Information Operations and Reports, 1215 Jeffer
Davis Highway, Suite 1204, Arlington, VA 22202-4302, and to the Office of Management and Budget, Paperwork Reduction Project (0704-0188), Washington, DC 20503.

\begin{tabular}{|l|l|r|}
\hline 1. AGENCY USE ONLY (Leave blank) & $\begin{array}{r}\text { 2. REPORT DATE } \\
\text { August } 1997\end{array}$ & $\begin{array}{r}\text { 3. REPORT TYPE AND DATES COVERED } \\
\text { Technical Memorandum }\end{array}$ \\
\hline
\end{tabular}

\section{TITLE AND SUBTITLE}

Laser Anemometer Measurements of the Flow Field in a 4:1 Pressure Ratio Centrifugal Impeller

6. AUTHOR(S)
5. FUNDING NUMBERS

WU-523-26-13-00

1L161102AH45

G.J. Skoch, P.S. Prahst, M.P. Wernet, J.R. Wood, and A.J. Strazisar

7. PERFORMING ORGANIZATION NAME(S) AND ADDRESS(ES)

NASA Lewis Research Center

Cleveland, Ohio 44135-3191

and

U.S. Army Research Laboratory

Cleveland, Ohio 44135-3191

9. SPONSORING/MONITORING AGENCY NAME(S) AND ADDRESS(ES)

National Aeronautics and Space Administration

Washington, DC 20546-0001

and

U.S. Army Research Laboratory

Adelphi, Maryland 20783-1145

8. PERFORMING ORGANIZATION REPORT NUMBER

\author{
E-10864
}

10. SPONSORING/MONITORING AGENCY REPORT NUMBER

NASA TM-107541

ARL-TR-1448

11. SUPPLEMENTARY NOTES

Prepared for the Turbo-Expo '97 sponsored by the International Gas Turbine Institute of the American Society of Mechanical Engineers, Orlando, Florida, June 2-5, 1997. G.J. Skoch, U.S. Army Research Laboratory, Lewis Research Center; P.S. Prahst, NYMA, Inc., 2001 Aerospace Parkway, Brook Park, Ohio 44142 (work funded under NASA Contract NAS3-27186); M.P. Wernet, J.R. Wood, and A.J. Strazisar, NASA Lewis Research Center. Responsible person, G.J. Skoch, organization code 0302, (216) 433-3396.

\begin{tabular}{|l|l}
\hline 12a. DISTRIBUTION/AVAILABILITY STATEMENT & 12b. DISTRIBUTION CODE
\end{tabular}

Unclassified - Unlimited

Subject Category 07

This publication is available from the NASA Center for AeroSpace Information, (301) 621-0390.

13. ABSTRACT (Maximum 200 words)

A laser-doppler anemometer was used to obtain flow-field velocity measurements in a 4:1 pressure ratio, $4.54 \mathrm{~kg} / \mathrm{s}$ (10 $\mathrm{lbm} / \mathrm{s}$ ), centrifugal impeller, with splitter blades and backsweep, which was configured with a vaneless diffuser. Measured through-flow velocities are reported for ten quasi-orthogonal survey planes at locations ranging from $1 \%$ to $99 \%$ of main blade chord. Measured through-flow velocities are compared to those predicted by a 3-D viscous steady flow analysis (Dawes) code. The measurements show the development and progression through the impeller and vaneless diffuser of a through-flow velocity deficit which results from the tip clearance flow and accumulation of low momentum fluid centrifuged from the blade and hub surfaces. Flow traces from the CFD analysis show the origin of this deficit which begins to grow in the inlet region of the impeller where it is first detected near the suction surface side of the passage. It then moves toward the pressure side of the channel, due to the movement of tip clearance flow across the impeller passage, where it is cut by the splitter blade leading edge. As blade loading increases toward the rear of the channel the deficit region is driven back toward the suction surface by the cross-passage pressure gradient. There is no evidence of a large wake region that might result from flow separation and the impeller efficiency is relatively high. The flow field in this impeller is quite similar to that documented previously by NASA Lewis in a large low-speed backswept impeller.

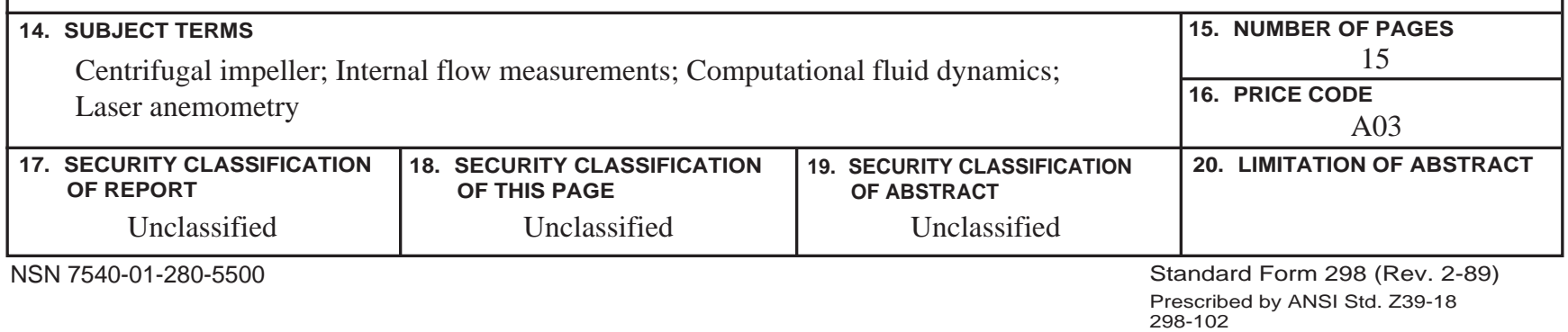

